\title{
Análisis de la cláusula de Nación Más Favorecida en los convenios para evitar la doble imposición: aspectos generales e implicaciones para el caso colombiano
}

\section{The Most Favored Nation Principle in Double Taxation Conventions: general aspects and implications in Colombian tax treaty practice}

\author{
Omar Sebastián Cabrera Cabrera ${ }^{1}$
}

\section{Resumen}

El otorgamiento de cláusulas de nación más favorecida nace bajo el marco de los acuerdos internacionales de índole comercial con la finalidad de promover y fomentar el intercambio económico. No obstante, su practicidad y características lograron que este tipo de estipulaciones fueran incorporadas de manera generalizada en los tratados de índole tributaria. De esta manera, en la práctica se evidencia la aceptación de estas formas jurídicas por parte de los Estados en la negociación de sus convenios para evitar la doble imposición. Colombia no ha sido ajena a este fenómeno, al optar incluir estos pactos como pauta general de negoción durante los primeros acuerdos tributarios firmados, lo cual generará un importante debate en torno a su aplicación práctica en el momento en el cual entre en vigor el tratado con el Reino Unido o Francia.

Palabras clave: Principio de Nación más Favorecida, Principio de trato nacional, Convenios para evitar la doble imposición, Prin-

\footnotetext{
${ }^{1}$ Abogado con profundización en Derecho Tributario y especialista en Derecho Económico Internacional de la Universidad Externado de Colombia. Especialista y magíster en Tributación de la Universidad de los Andes. Ha sido docente asistente de Derecho Tributario Internacional en la Universidad Externado y Universidad de los Andes e investigador del Centro Externadista de Estudios Fiscales y del Instituto Colombiano de Derecho Tributario. También cursó Diplomado en Impuestos de la facultad de Contaduría Pública de la Universidad Externado. Consultor tributario en PricewaterhouseCoopers Colombia. Correo-e: omarcabreracabrera@gmail.com DOI: https://doi.org/10.18601/16926722.n13.02
} 
cipio de no discriminación, Convención de Viena sobre el Derecho de los Tratados de 1969, GATT, GATS Y TRIPS.

\section{Abstract: \\ The granting of most-favored-nation clau- ses arises under the framework of interna- tional trade agreements with the purpose of promoting and spur economic exchange. However, its practicality and characteristics made that this type of clauses were widely incorporated in tax treaties. In this way, in practice the adherence of this type of clau- ses by the States in the negotiation of their Agreements to Avoid Double Taxation is evident. Colombia has not been oblivious to this phenomenon when opting to include the- se pacts as a general guideline of negotiation during the first signed tax agreements, which will generate an important debate towards its practical application at the moment in which the treaty either with the United Kingdom or France comes into force.}

Key words: Most Favored Nation principle, National Treatment Principle, Double Taxation Conventions, Principle of NonDiscrimination, 1969 Vienna Convention on the Law of Treaties, GATT, GATS, and TRIPS.

\section{Introducción}

En una economía mundial cada día más globalizada e interconectada, los mecanismos dirigidos a la prohibición del trato discriminatorio o la denominada no discriminación frente a ciudadanos, compañías, capitales y productos extranjeros, se han convertido en herramientas jurídicas indispensables para el fomento y patrocinio de las crecientes transacciones transfronterizas. Dicho esto, diferentes preceptos han sido agregados a las normas internas y a los acuerdos de índole comercial -ya sean multilaterales, regionales o bilaterales-, con miras a garantizar un trato equitativo y equiparable o, por lo menos, uno no menos favorable al otorgado a las personas, mercancías, capitales y servicios locales o nacionales.

No obstante lo anterior, las medidas antidiscriminatorias no han sido exclusivas de convenciones internacionales propias del mundo del Derecho económico internacional (DEI). A pesar de que históricamente nacieron en el desarrollo de las relaciones comerciales interestatales, estos elementos se han visto inmiscuidos en diferentes tipologías de tratados internacionales de distinta naturaleza. De tal suerte que es previsible toparse con estas formas de disposiciones en, por ejemplo, acuerdos de promoción y protección recíproca de inversiones (APPRI) y más puntualmente, en los convenios de doble imposición (CDI), a pesar de las grandes diferencias, no solo estructurales, sino teleológicas, entre los acuerdos comerciales $\mathrm{y}$ tributarios.

Una vez establecido el contexto general, el propósito del texto se enmarca principalmente en evaluar la aplicación de la cláusula de nación más favorecida contenida en los tratados tributarios, realizando un estudio general sobre las cláusulas de no discriminación vistas desde el DEI. De esta manera, para cumplir la finalidad del texto, se abordarán las siguientes temáticas: (i) una visión general del comercio internacional; (ii) características generales de la no discriminación en acuerdos comerciales y tributarios; (iii) 
entorno de la nación más favorecida y los CDI, y (iv) los pactos de nación más favorecida en los CDI suscritos por Colombia, para finalizar con unas conclusiones generales.

\section{La no discriminación en acuerdos de naturaleza comercial y el comercio internacional}

Indiscutiblemente, la celebración de acuerdos comerciales ha sido un mecanismo moderno que procura el fomento del intercambio de bienes, servicios y personas entre todas las economías del globo. De esta manera, está justificado que, sin perjuicio de visiones contrarias (Stiglitz, 2002), desde el punto de vista de la escuela económica de corte liberal, la integración de los mercados mundiales es algo que genera mayor bienestar para la población del mundo. De esta manera, puede señalarse que la Organización Mundial del Comercio (2001) ha realizado estudios en los cuales es posible concluir que el crecimiento económico está asociado con el libre intercambio mundial.

A raíz del nacimiento de las ciencias económicas y los llamados economistas clásicos, comienza el proceso de resaltar la importancia del libre comercio para el planeta. De esta manera, grandes exponentes de la economía, incluido su fundador Adam Smith, habían dedicado esfuerzos a demostrar cómo la libertad y apertura del comercio internacional generaban bienestar al mundo.

En este contexto, nace la famosa teoría de la ventaja comparativa en el comercio, cuyo máximo desarrollador fue David Ricardo. En términos generales, la teoría de la ventaja comparativa consiste en que cada país debe intercambiar con otros países el producto frente al cual tiene una ventaja en producción. A título de ilustración, David Ricardo ponía el ejemplo de Reino Unido y Portugal frente al vino y la tela. En la medida en que al Reino Unido le costaba menos producir tela, pero más producir vino, debía intercambiar sus telas por vinos portugueses, ya que a Portugal le resultaba más eficiente producir vinos que telas. Como puede verse, la lógica detrás del principio de la ventaja comparativa fue el motor ideológico del comercio internacional.

De otro lado, se evidenció que una de las grandes barreras al comercio eran las legislaciones internas de los Estados, por cuanto no existían reglas claras que dieran trato justo o por lo menos equitativo a los inversionistas extranjeros (Johnson y Gimblett, 2011). De esta manera, pueden ponerse de presente episodios famosos de la historia, como la llamada diplomacia de cañonero (gunboat diplomacy), en virtud de la cual los países desarrollados recurrían a operativos bélicos y militares para hacer honrar sus acreencias, toda vez que consideraban que la ley doméstica de sus deudores no era garantía para el cobro (Gwynn, 2016).

En el contexto anterior, nacen los primeros acuerdos para contribuir con el comercio internacional, denominados "acuerdos de amistad, comercio y navegación", mediante los cuales se creaba un marco jurídico idóneo entre dos Estados para fortalecer sus relaciones comerciales (Coyle, 2013). Dichos tratados se convirtieron en los embriones de lo que hoy conocemos como tratados de libre comercio o TLC. 
De otro lado, a raíz de la reunión de Bretton Woods sostenida en los Estados Unidos durante la Segunda Guerra Mundial, se propuso la creación de un nuevo orden económico mundial en el cual se eliminaran las barreras existentes al comercio, particularmente los aranceles de aduanas.

Esto derivó en la celebración del Acuerdo de la Habana de 1947, el cual preveía una eliminación paulatina a los aranceles. Sin embargo, dada la negativa de los Estados Unidos de participar, se hizo en la práctica nugatorio el pacto de la Habana (denominado GATT de 1947).

Sin embargo, los principios del pacto de la Habana fueron retomados durante la negociación de la llamada ronda de Marrakech, la cual finalizó en Uruguay con la creación de la Organización Mundial del Comercio (OMC). De esta manera, en el acuerdo constitutivo de la OMC fueron recogidos los principios del GATT del 1947 $\mathrm{y}$, adicionalmente, se establecieron acuerdos para la liberalización de los servicios en el Acuerdo General sobre Comercio de Servicios (GATS) y regla de propiedad intelectual en el Acuerdo sobre los Aspectos de los Derechos de Propiedad Intelectual relacionados con el Comercio (ADPIC o, en inglés, TRIPS).

Una vez establecido lo anterior, tanto los TLC como los acuerdos constitutivos del sistema de comercio internacional centralizados de la OMC incluyeron reglas de trato nacional (national treatment) y nación más favorecida (most favoured nation) como formas de evitar discriminaciones en el comercio internacional. Lo anterior sin dejar de mencionar que dichos principios aplican de manera restrictiva solo frente a los temas sobre los cuales fueron pactados.

Sentado lo anterior, a continuación, se realizará un análisis general y resumido de las definiciones de estos principios a la luz de los acuerdos de naturaleza comercial.

\section{A. Cláusula de trato nacional}

De acuerdo con Van Den Bossche (2017), la cláusula de trato nacional está definida de la siguiente manera:

La obligación de trato nacional exige que un Miembro de la OMC trate a los productos, servicios y proveedores de servicios extranjeros un trato no menos favorable el trato a productos, servicios y proveedores de servicios nacionales similares. Cuando se aplica la obligación de trato nacional, los productos extranjeros, por ejemplo, una vez que han cruzado la frontera e ingresado al mercado interno, no deben estar sujetos a impuestos o reglamentación menos favorable que los productos nacionales "similares". De conformidad con la obligación de trato nacional, un Miembro de la OMC no puede discriminar a los productos, servicios y proveedores de servicios extranjeros.

Así, puede verse que este principio aplica de manera vertical en la medida en que los bienes o servicios extranjeros o los proveedores de servicios extranjeros no pueden soportar un trato diferente al que reciben los productos, servicios o prestadores de servicios locales. Por dicho motivo, es sencillo comprender por qué el principio fue recogido por el Acuerdo General sobre Aranceles Aduaneros y Comercio de 1994 (GATT de 1994), el GATS y el ADPIC. 


\section{B. Cláusula de Nación Más Favorecida}

Los orígenes de este tipo de disposición pueden rastrearse desde normas comerciales del siglo XI. Así, durante la Edad Media, las principales ciudades comerciantes europeas procuraron acaparar el comercio con los territorios lejanos de África y el Medio Oriente (Naciones Unidas, 1969). De esta manera, la fórmula para lograr el cometido fue adoptar normas que obligaban hacer extensivo a otros países el trato comercial dado a una nación particular.

De esta manera, el principio de nación más favorecida se comenzó a utilizar de manera generalizada y, de esta forma, se ha convertido en piedra angular en el comercio internacional. Por dicho motivo, tal principio también fue agregado al GATT, el GATS y el ADPIC.

Por su parte, de acuerdo con Van Den Bossche (2017), el principio de Nación Más Favorecida en el marco de la OMC puede definirse como se presenta a continuación:

La obligación de trato de nación más favorecida exige a un Miembro de la OMC que otorga un trato favorable a otro país, el otorgar el mismo trato favorable a todos los demás países Miembros de la OMC. Un Miembro de la OMC no puede discriminar entre sus socios comerciales, por ejemplo, otorgando a los productos importados de algunos países un trato más favorable con respecto al acceso a los mercados frente al trato que otorga a los productos de otros Miembros. La obligación de trato de nación más favorecida es la regla más importante en el derecho de la OMC. Sin esta regla, el sistema multilateral de comercio podría no existir.

En la forma en que se evidencia, a diferencia de lo que ocurre con el principio del trato nacional, en el principio de nación más favorecida existe una aplicación horizontal en la medida en que cualquier gabela, ya sea en bienes o servicios, que se otorgue a un país debe ser inmediatamente otorgada a los otros Estados; en palabras más sencillas, si un Estado otorga manzanas a otro Estado, este último deberá hacer extensivas tales manzanas a todos los otros Estados miembros.

\section{El principio de Nación Más \\ Favorecida en los tratados tributarios}

\section{A. Historia, posición de la OCDE y la doctrina}

Primeramente, debe hacerse hincapié en que las bases fundacionales de los CDI modernos se derivan de las conclusiones generales del informe de los expertos económicos (Bruins, Seligman, Stamp y Einaudi) de 1922 sobre los aspectos generales de la doble imposición internacional y solicitado por la Liga de las Naciones (Cabrera Cabrera, 2017). De esta manera, con ocasión de la revisión de dicho informe por parte de los expertos gubernamentales de la extinta Liga de las Naciones (LDN) en 1929, se hicieron las primeras referencias a la posible aplicación de cláusulas de nación más favorecida en acuerdos tributarios. Dicho lo anterior, tal informe señalaba al respecto que:

La Reunión General de Expertos Gubernamentales también recomendó que el Comité proceda con "el examen de todos los puntos 
del derecho internacional relacionados con la doble imposición, como la reciprocidad y las relaciones entre la cláusula de la nación más favorecida y las cuestiones de la doble imposición”.

Un intercambio preliminar de puntos de vista sobre estos puntos mostró que eran muy complejos. Por lo tanto, el Comité Fiscal propone estudiarlos nuevamente en su próxima sesión.

Como puede verse, a pesar de que ya se hacía alusión al tema, se decidió que, por motivos de la dificultad y complejidad del tópico, este último tuviese que ser abordado nuevamente en otra reunión del comité.

Posteriormente, al año siguiente, el tema fue nuevamente discutido a mayor profundidad por el comité, en donde se señaló que:

Teniendo en cuenta que los acuerdos bilaterales o multilaterales sobre doble imposición se basan en el principio de reciprocidad, es decir, implican un trato recíproco para los nacionales de las partes contratantes, el Comité Fiscal, aunque no desea emitir opinión sobre un punto extremadamente difícil del derecho internacional, considera que la aplicación de la cláusula de la nación más favorecida a los nacionales de un país que no se haya adherido a dichos acuerdos constituiría un trato de esos nacionales en contra de la equidad y al espíritu de la nación cláusula.

No obstante, para evitar que surja este punto, es deseable que en los tratados comerciales celebrados en el futuro quede claro que aplicación de la cláusula de la nación más favorecida a cuestiones fiscales no se extiende a disposiciones especiales para evitar la doble imposición. (destacado fuera de texto).

Así las cosas, la primera conclusión consistió en aseverar la incompatibilidad de la cláusula de nación más favorecida con un acuerdo tributario, dado que sería algo en contra de la equidad y la finalidad de la cláusula dada la naturaleza recíproca de los CDI. Adicionalmente, se sugería aclarar en los acuerdos comerciales que la cláusula de nación más favorecida contenida allí no podía hacerse extensiva a los CDI.

De esta manera, los expertos gubernamentales de manera consistente en 1929 y 1930 concluyeron que estas cláusulas eran incompatibles con los CDI dado que la naturaleza eminentemente bilateral de estos últimos desvirtuaba el elemento de reciprocidad que debía existir en los acuerdos tributarios. En palabras más claras, que los CDI se fundamentaban en la renuncia del ejercicio del poder impositivo en donde cada Estado contratante cedía de manera bilateral y recíproca su tributación sin que fuera posible extender estas reglas a terceros países que no eran parte del acuerdo.

Sin embargo, unos años después, en 1946, el comité nuevamente se reunió con la finalidad de discutir los modelos de convenio de México (1943) y de Londres (1946), y en dicha ocasión hubo una nueva manifestación frente a la compatibilidad de los CDI y el principio de nación más favorecida. En dicho caso, se sostuvo que:

Una cuestión que ha surgido de vez en cuando es la aplicación de la cláusula de la nación más favorecida en relación con los 
tratados fiscales. En el pasado, la opinión era que tales tratados están supeditados a concesiones mutuas sobre una base bilateral. En consecuencia, tales tratados no entrarían en el campo ordinario de aplicación de la cláusula. Sin embargo, en vista de la estrecha interrelación entre los tratados tributarios y comerciales, podría ser conveniente examinar nuevamente si los tratados tributarios no deberían formularse de forma que permitan la aplicación de la cláusula de la nación más favorecida.

En la forma en que se evidencia, ya para 1946, la Liga de Naciones estaba cuestionando sus conclusiones de los años 30, dejando la puerta abierta a hacer una reformulación de su postura. Sin embargo, y por motivo de que su desarrollo no es propósito del texto, la LDN fue oficialmente liquidada y, con ello, cualquier nuevo intento por hacer un mayor análisis del tema.

Como es conocido, fue la Organización para la Cooperación Económica Europea (OEEC) - precursora de la OCDE- la entidad que continuó con los hilos del desarrollo de los modelos de convenio, reemplazando de manera clara a la LDN en asuntos tributarios.

Así las cosas, la primera vez que el tópico de nación más favorecida fue tocado por parte de la OCDE, se optó por acoger un raciocinio similar al sostenido por la LDN en los años 30. En ese sentido, dicha manifestación fue recogida por los comentarios del Modelo de Convenio de la OCDE (MOCDE) de 1977, en los cuales se dispuso que:

Siempre se ha aceptado que tal cláusula no se aplica en el caso de los convenios de doble imposición porque se basan esencialmente en el principio de reciprocidad.

A pesar de que el comentario anterior fue eliminado en la actualización del MOCDE de 1994, en el MOCDE de 2010 se retomó la postura institucional de la OCDE de sostener de manera clara la incompatibilidad de las cláusulas de nación más favorecida y los CDI. De esta manera, el comentario 2 al artículo 24 del MOCDE señala que:

Del mismo modo, las disposiciones del artículo no pueden interpretarse en el sentido de exigir el tratamiento de nación más favorecida. Cuando un Estado haya celebrado un convenio bilateral o multilateral que suponga beneficios fiscales para los nacionales o residentes del otro u otros Estados contratantes que sean parte del convenio, los nacionales o residentes de un tercer Estado, no incluido entre los signatarios, no podrán optar a los beneficios del convenio por razón de una cláusula similar sobre no discriminación contenida en el convenio celebrado entre el tercer Estado y el Estado mencionado en primer lugar. Dado que los convenios tributarios se basan en el principio de reciprocidad, el tratamiento tributario concedido por uno de los Estados contratantes en virtud de un convenio bilateral o multilateral a un residente o nacional de otro Estado contratante que sea parte de ese convenio, por razón de la relación económica concreta entre ambos Estados contratantes, no puede extenderse a un residente o nacional de un tercer Estado en virtud de la cláusula de no discriminación del convenio entre el primer y el tercer Estado (destacado fuera de texto). 
En definitiva, la posición actual de la OCDE se resume en el desarrollo histórico del tema, es decir, tomar la postura de señalar la naturaleza antagónica entre los OCDE y el principio de nación más favorecida.

De otro lado, es preciso señalar que la principal doctrina al respecto, es decir, Radler (1996) y Pistone (2002), ha concordado en señalar su aprobación a la visión de la OCDE señalada anteriormente.

\section{B. Una mirada a la nación más favorecida en la red mundial de acuerdos de doble tributación}

De acuerdo con Hofbauer (2005), la primera cláusula de nación más favorecida incluida en un CDI puede rastrearse al tratado tributario suscrito por Sri Lanka (en ese momento conocido como Ceilán) y Japón en diciembre de 1967. Sentado lo anterior, este CDI, hito en la materia, establecía una regla de nación más favorecida respecto de regalías, las cuales se encontraban reguladas en el Artículo VIII de dicho tratado. Así, la primera cláusula de nación más favorecida en un acuerdo tributario estaba redactada de la siguiente manera:

Las disposiciones del párrafo 2 del Artículo VIII del Convenio se modificarán si el Gobierno de Ceilán otorga a otro país cualquier concesión adicional a la prevista en dichas disposiciones del Convenio, de modo que la misma concesión otorgada a ese otro país se otorgue entregados a Japón y entrarán en vigor a partir del primer día de abril del año calendario en que la concesión sea aplicable a ese otro país.
De manera curiosa, el segundo CDI con estos pactos también fue suscrito por Japón, con lo cual puede indicarse que fue una práctica iniciada por dicho país asiático. En ese sentido, el segundo avistamiento fue en el CDI concluido entre Japón y Holanda, en donde no solo fue prevista para regalías, sino que, adicionalmente, fue aplicable para intereses y dividendos.

A raíz de estos dos CDI, se inició la práctica, en algún sentido general, de incluir cláusulas de nación más favorecida, que no solo fueron concedidas para rentas pasivas (dividendos, intereses o regalías), sino también para otros elementos de renta como, por ejemplo, las ganancias de capital por los servicios personales independientes.

De otro lado, Hofbauer (2005) señala que fueron los años noventa los que evidenciaron el mayor crecimiento de CDI con cláusulas de nación más favorecida por los siguientes motivos: i) la posible obligación de trato de nación más favorecida a nivel europeo; (ii) la terminación de las negociaciones de la Ronda Uruguay en la OMC; (iii) la conclusión del TLCAN en Norteamérica; (iv) el aumento general en el número de acuerdos bilaterales y tratados tributarios, especialmente después de que el Bloque del Este colapsó y, en consecuencia, la necesidad de negociar tratados completamente nuevos en pro de continuar con la globalización económica.

Basados en el estudio realizado por Hofbauer (2005) en lo que respecta a la distribución geográfica de los CDI con cláusulas de nación más favorecida, se tiene que de 1.134 posibles tratados con tales cláusulas, 493 de ellos $(43,5 \%)$ corresponden a Euro- 
pa, 227 (es decir, 20\%) a Asia, 140 (es decir, $12,4 \%)$ a América del Norte, $99(8,7 \%)$ a Centro y Sudamérica, 65 (es decir, el 5,7\%) a Oceanía, 57 (es decir, el 5\%) a la Península Arábiga y, finalmente, 53 CDI (es decir, el $4,7 \%)$ a África.

\section{Las cláusulas de nación más favorecida en los acuerdos tributarios concluidos por Colombia}

Como primer punto, debe señalarse que a raíz de la firma del CDI con España en el año 2005, Colombia abandonó su postura de no querer celebrar acuerdos tributarios (Cabrera Cabrera, 2016; Mosquera, 2013, y Quiñones, 2012). A partir de ese momento, el país inició una ola de suscripción del CDI con diferentes Estados como parte de una política pública de atracción de inversión.

A la fecha, se han suscrito CDI con España, Chile, Canadá, México, Corea, India, Portugal y República Checa, los cuales se encuentran actualmente vigentes. No obstante, también se han firmado acuerdos con Francia, Reino Unido, Emiratos Árabes Unidos e Italia, los cuales pronto entrarán en vigor.

Ahora bien, es preciso poner de presente una característica fundamental de la primera ola de CDI concluidos. Así las cosas, en las negociaciones bilaterales se logró incluir dentro de la definición de regalías los servicios técnicos, de asistencia técnica y de consultoría. De esta manera, en caso del pago de alguno de estos servicios antes referidos, el país de la fuente podrá gravarlos a través de retención en la fuente, ya que, bajo las normas genéricas del MOCDE, serían calificados como beneficios empresariales que solo podrían gravarse en la fuente en la medida en que les sean imputables a un establecimiento permanente situado allí.

Esta política de incluir los servicios técnicos (technical fees) dentro del ámbito de aplicación objetivo de las regalías nace de la postura de la India, la cual advirtió que gran parte de la tributación se veía erosionada en ese país cuando la operación tenía lugar con un país con el cual se había celebrado un CDI; lo anterior en la medida en que, al ser un país importador de tecnología y capital, gran parte de los servicios prestados desde el exterior consistían en servicios que involucraban tecnología y, por tanto, estaban sometidos a retención en la fuente bajo la norma doméstica.

Una vez señalado lo anterior, es importante hacer hincapié en que, para el caso colombiano, la condición para que fuera incluida la regla de los servicios técnicos, de asistencia técnica y consultoría, fue establecer cláusulas de nación más favorecida de aplicación inmediata con los países con los cuales se negoció un CDI, como forma de quid pro quo o retribución a la contraparte.

Por dicho motivo, es posible encontrar cláusulas de este tipo en el texto de los CDI que actualmente están en vigor, aunque debe indicarse que no todas están redactadas de manera idéntica. Adicionalmente, para algunos CDI, también es posible encontrar cláusulas de nación más favorecida aplicables al artículo de los intereses. Adicionalmente, partiendo de la óptica de la Convención de Viena sobre el Derecho de los Tratados de 1969, los Estados son libres de acordar las disposiciones que consideren necesarias como manifestación de la figura del pacta sunt servanda. 
No obstante, debe indicarse que la firma del CDI con Francia marcó un nuevo inicio en lo que respecta al punto de los servicios técnicos, de asistencia técnica y consultoría. De manera sorpresiva, se abandonó la postura que se había venido manejando y, por dicho motivo, el tratado no incluyó estos servicios dentro de la definición de regalías, con lo cual, sería aplicable la regla distributiva de los beneficios empresariales. Adicionalmente, a partir de ese momento, los CDI que fueron suscritos con posterioridad, como, por ejemplo, con el Reino Unido o los Emiratos Árabes Unidos, siguieron esta nueva postura.

De esta manera, en la medida en que el CDI con Francia y el Reino Unido se encuentran actualmente en proyecto de ley en el legislativo (Proyecto de Ley 163 de 2017 y Proyecto de Ley 162 de 2017, respectivamente), se hace necesario hacer un análisis de lo que ocurriría con las cláusulas de nación más favorecida de los otros CDI, en el momento en que entren en vigor los CDI mencionados en primer lugar. En consecuencia, a continuación, se hará un análisis de cada una de dichas clausulas en los CDI que las han incluido.

\section{A. España}

En la medida en que con España fue suscrito el primer CDI, fue la primera vez en la que se tuvo conocimiento en Colombia sobre la aplicación de cláusulas de nación más favorecida en acuerdos de doble tributación. Así, en el protocolo del CDI con España, se señala la aplicación de cláusula para intereses que está redactada de la siguiente manera:

\section{Ad. Artículo 11}

2. En el caso de que Colombia, después de firmado este presente Convenio, acordara con un tercer Estado un tipo impositivo sobre intereses inferior al establecido en el artículo 11 o una exención distinta a las contempladas en dicho artículo del presente Convenio ese nuevo tipo impositivo o exención se aplicará automáticamente al presente Convenio como si constara expresamente en el mismo; surtirá efectos desde la fecha en la que surtan efectos las disposiciones del Convenio firmado con ese tercer Estado.

Como puede verse, la aplicación de la cláusula puede presentarse en dos eventos: (i) cuando se acuerde posteriormente un mejor tipo impositivo con un tercer Estado o (ii) cuando se acuerde posteriormente una exención diferente con un tercer Estado a las previstas en el CDI con España. Más aun, se dispone que lo acordado con el tercer país se entenderá adicionado al texto CDI sin necesidad de que exista una modificación o adición al mismo. Adicionalmente, la aplicación se hará de manera inmediata a partir del momento en que surta efectos el convenio con el tercer Estado.

Por su parte, entendemos que el concepto de tipo impositivo puede darse por dos condiciones. La primera es que pacte una menor tarifa de imposición de retención en la fuente para intereses, lo cual, a la fecha, no ha ocurrido, ya que no se ha fijado en ningún CDI posterior una tarifa inferior al $10 \%$. La segunda es que, por virtud de un CDI con un tercer Estado, se aplique una nueva regla distributiva que sea en términos tributarios más favorable.

Así las cosas, consideramos que frente a la entrada en vigor del acuerdo con Francia 
o Reino Unido será aplicable ya que deberá darle uso a la regla distributiva de los beneficios empresariales en reemplazo de la cláusula de las regalías.

De otro lado, el CDI con España también establece la cláusula de nación más favorecida para regalías, la cual está redactada de manera análoga a la de los intereses antes citada. Así, dicha cláusula señala que

\section{Ad. Artículo 12}

3. En el caso de que Colombia, después de firmado este presente Convenio, acordara con un tercer Estado un tipo impositivo sobre cánones o regalías inferior al establecido en el artículo 12 del presente Convenio, ese nuevo tipo impositivo se aplicará automáticamente al presente Convenio como si constara expresamente en el mismo; surtirá efectos desde la fecha en la que surtan efectos las disposiciones del Convenio firmado con ese tercer Estado.

\section{B. Suiza}

Al igual que el CDI con España, en el acuerdo con Suiza también se fijaron cláusulas de nación más favorecida, no solo para intereses, sino también para regalías. En ese sentido, el protocolo del CDI con Suiza dispone que:

\section{AD Artículo 11}

a) En el caso de que Colombia, después de firmado este presente Convenio, acordara con un tercer Estado un tipo impositivo sobre intereses inferior al establecido en el artículo 11 o una exención distinta a las contempladas en dicho artículo del presente Convenio, ese nuevo tipo impositivo o exención se aplicará automáticamente al presente Convenio como si constara expresamente en el mismo; surtirá efectos desde la fecha en la que surtan efectos las disposiciones del Convenio firmado con ese tercer Estado.

De la forma en que puede evidenciarse, la redacción de esta norma es bastante análoga en su redacción a la del CDI con España, hasta el punto de señalar que se trata de una copia. Así, también se prevé una aplicación inmediata en lo que respecta a un nuevo tipo impositivo o exención, al igual que se incluyen las demás características señaladas para el caso colombo-español.

Ahora bien, la norma de nación más favorecida para las regalías está redactada como se presenta a continuación:

\section{AD Artículo 12}

En el caso de que Colombia, después de firmado este presente Convenio, acordara con un tercer Estado un tipo impositivo sobre cánones o regalías inferior al establecido en el artículo 12 del presente Convenio, ese nuevo tipo impositivo se aplicará automáticamente al presente Convenio como si constara expresamente en el mismo; surtirá efectos desde la fecha en la que surtan efectos las disposiciones del Convenio firmado con ese tercer Estado.

Como puede verse, también es una copia de la norma del CDI con España, con lo cual son aplicables a cabalidad los comentarios antes analizados.

\section{Canadá}

A diferencia de los CDI con Suiza y España, la cláusula de nación más favorecida 
contenida en el protocolo del CDI con Canadá solo es aplicable para regalías y no para intereses. Sentado lo anterior, la cláusula está escrita de la siguiente manera:

Si después de firmado el Convenio, Colombia suscribe con un Estado tercero un Convenio que estipule disposiciones respecto de asistencia técnica, servicios técnicos o servicios de consultoría que sean más favorables que aquellas pospuestas en el artículo 12 del Convenio, dichas disposiciones aplicarán automáticamente al Convenio, bajo las mismas condiciones, como si dichas disposiciones se hubieren establecido en el Convenio. Dichas disposiciones aplicarán a este Convenio a partir de la entrada en vigor del Convenio con el Estado tercero. La autoridad colombiana competente le deberá informar a la autoridad canadiense competente, sin demora, que se han cumplido las condiciones de aplicación de este subpárrafo.

Resulta particular esta cláusula, toda vez que de manera expresa se ve limitada solo a eventos en los cuales se pacten condiciones más favorables con un tercer país en lo que respecta a los servicios técnicos, asistencia técnica y consultoría. Desde ya puede advertirse que los CDI con España y Suiza se hace referencia en general a regalías y, no puntualmente, a los servicios antes reseñados.

De esta forma, en la medida en que la aplicación de los CDI con Francia y Reino Unido derivaría en un tratamiento más favorable ya que no habría retención en la fuente en Colombia.

Naturalmente, la cláusula será aplicable inmediatamente sin perjuicio de que la au- toridad competente en Colombia le deba notificar sin retardo el momento en el cual podrá hacerse efectiva la cláusula, lo cual, consideramos, deberá hacerse en el momento de incorporación interna del CDI con Francia o el Reino Unido.

\section{Chile}

Al igual que el CDI con Canadá, para el caso colombo-chileno se previó la cláusula de nación más favorecida solamente para regalías. De esta manera, el protocolo del tratado con Chile establece que

\section{Ad. Artículo 12.}

Si Colombia concluye un Convenio con un tercer Estado en el que se modifique la imposición en el país fuente de los pagos por asistencia técnica, servicios técnicos o servicios de consultoría que se contemplan en el artículo 12 de este Convenio, tales modificaciones se aplicarán al presente Convenio como se indica a continuación:

En el caso que se acuerde una exención o una alícuota menor en dicho Convenio tal exención o alícuota menor se aplicará automáticamente a este Convenio. La exención o la reducción de la alícuota se aplicará a este Convenio a partir de la fecha de entrada en vigor del Convenio con el otro Estado, bajo las mismas condiciones como si esa exención o alícuota menor hubiera sido especificada en este Convenio. La autoridad competente de Colombia informará, sin demora, a la autoridad competente de Chile, que se han cumplido las condiciones para la aplicación de este párrafo.

Como se ve, la redacción señala que es aplicable cuando se fije con un tercer país 
una exención o alícuota menor. Así las cosas, consideramos que una exención como lo requiera la cláusula puede darle en el caso en el cual, por motivo de la entrada en vigor de un CDI con un tercer Estado, se deba aplicar una nueva calificación que genere una menor tributación, algo que, como ya se mencionó, ocurriría con los CDI con Francia o Reino Unido.

\section{E.México}

De forma análoga a los CDI con Chile y Canadá, para el caso mexicano, la cláusula está ceñida exclusivamente a las regalías. De esta manera, el protocolo del convenio fiscal con México señala que:

4. En relación con el Artículo 12 se entiende que

a) En el caso de que Colombia, después de firmado este Convenio, acordara con un tercer Estado una tasa impositiva sobre regalías aplicable a los pagos por asistencia técnica y servicios técnicos que sea inferior a la establecida en el artículo 12 del presente Convenio, o bien, considera dichos pagos con una naturaleza distinta a la de regalías, esa nueva tasa impositiva o naturaleza se aplicará automáticamente al presente Convenio como si constara expresamente en el mismo y surtirá efectos desde la fecha en la que sean aplicables las disposiciones del Convenio firmado con ese tercer Estado.

De la manera en que se desprende de la redacción, la cláusula será efectiva no solo si se fija con otro país una menor tarifa de retención para regalías, sino, adicionalmente, cuando dichos pagos deben tener una nueva naturaleza. Así las cosas, para este caso, es completamente claro que sí será efectivo cuando se inicie la vigencia de los CDI con Francia y Reino Unido, ya que, como se ha señalado reiteradamente, bajo estos últimos acuerdos estos servicios tendrán la nueva calificación de beneficio empresarial.

\section{F. Portugal}

De forma análoga a los CDI con Chile, Canadá y México, para el caso con Portugal, la cláusula está restringida de manera privativa para la tributación de regalías. De esta manera, el protocolo del CDI con Portugal dispone que:

5. En relación con el artículo 12 a) Si, después de la firma el Convenio, Colombia concluye con un tercer Estado un Convenio que incluya disposiciones relativas a la asistencia técnica, servicios técnicos o servicios de consultoría que son más favorables que los previstos por el artículo 12 del Convenio, dichas disposiciones se aplicarán automáticamente al Convenio, bajo las mismas condiciones como si ellas hubieran sido incluidas en el Convenio. Dichas disposiciones se aplicarán al Convenio desde la fecha de entrada en vigor del Convenio con el tercer Estado. La autoridad competente de Colombia informará sin demora a la autoridad competente de Portugal que las condiciones de aplicación del presente apartado se han cumplido.

El apartado del protocolo deja claro que la cláusula deberá aplicarse en cualquier caso en el cual un CDI celebrado con un tercer país genere un tratamiento más beneficioso. Por ende, en la medida en que resultan más beneficiosos los CDI con Francia y Reino Unido, 
ya que en estos casos no existirá retención en la fuente, la cláusula será efectiva.

\section{G. República Checa}

A diferencia de los CDI antes referidos, el tratado con la República Checa prevé la cláusula directamente en el artículo de las regalías y no en el protocolo. Una vez hecha esta aclaración, la cláusula está redactada de la siguiente manera:

7. Si, después de la firma del presente Acuerdo, Colombia firma con un tercer Estado un Acuerdo, Convenio o un Protocolo al mismo que contenga disposiciones relacionadas con la imposición de rentas por la prestación de servicios de asistencia técnica, servicios técnicos o servicios de consultoría que sean más favorables que aquellas dispuestas en el presente Acuerdo, con respecto a la tarifa o tratamiento tributario o ambos, dicho régimen será automáticamente aplicable para efectos del presente Acuerdo, a partir de la fecha en la cual el Acuerdo, Convenio o Protocolo al mismo entre Colombia y ese tercer Estado produzca efectos. La autoridad competente de Colombia informará a la autoridad competente de la República Checa, sin demora, que las condiciones de aplicación del presente Acuerdo han cambiado.

Para este caso, se optó por supeditar la aplicabilidad de la cláusula a los eventos en los cuales un CDI posterior contemple un tratamiento más favorable, al igual que con el CDI con Portugal y República Checa, con lo cual, serán aplicables los comentarios ya realizados para estos casos puntuales.

\section{Conclusiones}

Los acuerdos de comercio han sido piezas claves para el patrocinio de la globalización económica. De esta manera, para evitar las barreras discriminatorias al comercio, dichos tratados han optado por incorporar principios de trato nacional y nación más favorecida.

De esta manera, la cláusula de nación más favorecida ha sido incluida de manera consensuada en algunos CDI particulares. Históricamente, tanto la LDN como la OCDE y la doctrina especializada han concluido que dichos pactos son contrarios a los principios funcionales de los CDI, en la medida en que son antagónicos a la naturaleza recíproca que existe en el funcionamiento de un tratado tributario.

Colombia no ha sido ajena a esta realidad $\mathrm{y}$, a raíz de la celebración del primer CDI con España, fue prevista una cláusula de nación más favorecida, no solo para regalías, sino también, en algunos casos, para intereses. De esta manera, esta práctica fue replicada en la primera ola de CDI, que consiste en todos aquellos tratados firmados antes del CDI con Francia.

El motivo de la inclusión de estos pactos en los acuerdos colombianos corresponde principalmente a una compensación por la inclusión de los servicios técnicos, de asistencia técnica y consultoría dentro del ámbito de aplicación de la norma distributiva de regalías, generando que puedan ser gravados en la fuente mediante el mecanismo de la retención en la fuente. 
Lo anterior, sin dejar a un lado que, sin dicho precepto especial, estos servicios tributarían como beneficios empresariales bajo la cláusula del Artículo 7 de los convenios, con lo cual, solo podrían gravarse en el país de la fuente en la medida en que le sean atribuibles a un EP situado en dicho lugar, con lo cual, no habría retención en la fuente por un pago al exterior.

A pesar de que la redacción de las cláusulas colombianas de nación más favorecida no han sido uniformes, sí se pueden establecer algunas similitudes. De esta manera, en lo que respecta a los CDI con Suiza y España, el principio de nación más favorecida es aplicable si se genera un nuevo tipo impositivo con ocasión a la vigencia de un CDI con un Estado diferente. Así, entendemos que nuevo tipo impositivo también se refiere a una nueva calificación en la regla distributiva, lo que pasará eventualmente en una entrada en vigor de los CDI con Francio o Reino Unido.

Para el caso de México, es bastante clara la aplicación de la cláusula, ya que esta aplicará también cuando un CDI con otro país genere una nueva calificación, lo que ocurre ya que serían beneficios empresariales y no regalías.

Frente a República Checa, Canadá y Portugal, señalan que es aplicable en cualquier caso en que un CDI con un tercer país genera un tratamiento más favorable, lo cual es claro en la medida en que no habría retención en la fuente por concepto de regalías.

De esta manera, señalamos como conclusión general que los pactos de nación más favorecida de los CDI de Colombia deberán hacerse efectivos en el evento en el cual el
CDI con Francia o Reino Unido entre en vigor, sin olvidar mencionar que ambos tratados ya se encuentran en trámite legislativo.

\section{Referencias}

Cabrera Cabrera, Omar Sebastián (2017). Aspectos tributarios de las plataformas digitales en Colombia: actualidad y retos. Revista de Derecho Fiscal X.

Cabrera Cabrera, Omar Sebastián (2016). El establecimiento permanente: especial énfasis en la Cláusula de agencia. Universidad Externado de Colombia.

Convención de Viena sobre el Derecho de los Tratados de 1969.

Convenio entre el Reino de España y la República de Colombia para evitar la doble imposición y prevenir la evasión fiscal en materia de impuestos sobre la renta y sobre el patrimonio y su protocolo. Aprobado mediante Ley 1082 de 2006.

Convenio entre la República de Canadá y la República de Colombia para evitar la doble imposición y para prevenir la evasión fiscal en relación con el impuesto sobre la renta y sobre el patrimonio y su protocolo. Aprobado mediante Ley 1459 de 2011.

Convenio entre la República de Chile y la República de Colombia para evitar la doble imposición y para prevenir la evasión fiscal con relación al impuesto a la renta y al patrimonio y su protocolo. Aprobado mediante Ley 1261 de 2008.

Convenio entre la República de Colombia y la Confederación Suiza para evitar la doble imposición en materia de impuestos sobre la renta y el patrimonio y su protocolo. Aprobado mediante Ley 1344 de 2009.

Convenio entre la República de Colombia y la República Checa para evitar la doble imposición y para prevenir la evasión fiscal en relación con el impuesto sobre la renta. Aprobado mediante Ley 1690 de 2013.

Convenio entre la República de Colombia y los Estados Unidos Mexicanos para evitar la doble imposición y para prevenir la evasión fiscal en relación con los impuestos sobre la renta y sobre el patrimonio y su protocolo. Aprobado mediante Ley 1568 de 2012.

Convenio entre la República Portuguesa y la República de Colombia para evitar la doble imposición y para prevenir la evasión fiscal en relación con el impuesto sobre la renta y su protocolo y el canje de notas entre 
la República Portuguesa y la República de Colombia, por medio del cual se corrigen imprecisiones en la traducción en las versiones en español, inglés y portugués del "Convenio entre la República Portuguesa y la República de Colombia para evitar la doble imposición y para prevenir la evasión fiscal en relación con el impuesto sobre la renta", aprobado mediante Ley 1692 de 2013.

Coyle, John F. (2013). The Treaty of Friendship, Commerce, and Navigation in the Modern Era. Columbia Journal of Transnational Law.

Gwynn, Maria A. (2016). Power in the International Investment Framework. Macmillan.

Hofbauer, Ines (2005). Most-Favoured-Nation Clauses in Double Taxation Conventions: A Worldwide Overview. Intertax.

Johnson Jr., Thomas \& Gimblett, Jonathan (2011). From gunboats to BITs: The evolution of modern international investment law en Yearbook on International Investment Law \& Policy 2010-2011. Oxford University Press.

Mosquera Valderrama, Irma Johanna (2013). The International Tax Treaty Policy of Colombia. Bulle- tin for International Taxation, vol. 67, Issue n. 4-5. Marzo 2013.

Pistone, Pasquale (2002). The Impact of Community Law on Tax Treaties: Issues and Solutions. Kluwer Law.

Quiñones Cruz, Natalia (2012). Colombia Report, en Lang et al. (eds.) The Impact of the OECD and UN Model Conventions on Bilateral Tax Treaties. Cambridge Tax Law Series.

Radler, Albert (1996). Most-Favored-Nation Concept in Tax Treaties, en Lang et al. (eds.). Multilateral Tax Treaties. Kluwer Law.

Stiglitz, Joseph (2002). El malestar de la globalización. Laurus.

United Nations (1969). Yearbook of the International Law Commission.

Van Den Bossche, Peter (2017). The Law and Policy of the World Trade Organization Text, Cases and Materials. Cambridge University Press.

World Trade Organization (2001). Trading into the Future. Marzo 2001. 